\title{
AVALANCHE ACTIVITY ON THE VAUGHAN LEWIS ICEFALL, ALASKA
}

\author{
By Alfred C. Pinchak \\ (Case Western Reserve University, Cleveland, Ohio 44to6, U.S.A.)
}

\begin{abstract}
Anstract. Avalanche data were obtained by direct observation of the Vaughan Lewis Icefall. Magnitude, time and location of each ice fall were recorded and the resulting data were analyzed statistically. An inverse relationship was found between the relative frequency and the magnitude of the avalanches, A significant diurnal variation in avalanche rate was also detected. During the early morning hours the avalanche rate reached a maximum. No secondary increase in the avalanche frequency was observed during the evening cooling period. The data indicated that a given ice fall results in an increased probability of an ice fall occurring shortly thereafter. After approximately 4 min the effect of a given avalanche no longer correlates with succeeding avalanches.
\end{abstract}

Réstwé. Étude de l'activité d'azalanches sur le Vaughan Leneis Icefall. Alaska. Des donnèes sur les avalanches ont été obtenues par observation directe du Vaughan lewis Icefall. Magnitude. temps et location de chaque chute de glace ont été notés et les données obtenues ont été sousmises à l'analyse statistique. On a trouvé une relation inverse entre la fréquence relative et la magnitude des avalanches. On a aussi détecté une variation diurne significative du nombre d'avalanches. Pendant les heures très matinales, le nombre d'avalanches atteint son maximum. Il n'a pas été observé d'augmentation secondaire de la fréquence des avalanches pendant la période de refroidissement du soir. Les données indiquent qu'une chute de glace donnéc résulte avec une probabilité croissante d'une autre chute de glace ayant lieu juste après la première. Après un temps d'environ 4 min. une avalanche donnée n'a plus de corrélation avec les avalanches suivantes.

Zusammenfassuxg. Lawinentätigkeit am Vaughan Lewis Icefall. Alaska. Unmittelbare Beobachtungen des Vaughan Lewis Icefall lieferten Lawinendaten, Grösse, Zeit und Ort jedes Eissturzes wurden registriert und dann statistisch analysiert. Es wurde eine inverse Bezichung zwischen der relativen Häufigkeit und Grösse der Lawinen festgestellt. Ausserdem ergab sich ein beträchtlicher Tagesgang der Lawinenhäufigkeit. Sie erreichte in den frühen Morgenstunden ein Maximum. Ein sekundärer Anstieg während der abendlichen Abkühlungsperiode wurde nicht beobachtet. Die Daten weisen darauf hin. dass auf einen bestimmten Eisfall mit erhöhter Wahrscheinlichkeit kurz darauf ein weiterer Eisfall folgt. Nach etwa 4 min ist der. Abgang einer Lawine nicht mahr mit folgenden Lawinen zu korrelieren.

\section{INTRODUCTION}

A very active ice fall* comprises part of the Vaughan Lewis Glacier which is located in the Juneau Icefield north-east of Juneau, Alaska. This ice fall is fed by a néré zone, at a mean altitude of $1680 \mathrm{~m}$ with a total accumulation area of approximately $26 \mathrm{~km}^{2}$. The ice fall is approximately a kilometer wide and drops through $500 \mathrm{~m}$ where it meets two other glaciers; on the left an unnamed glacier and the Gilkey Glacier on the right. These three ice streams merge and flow down-stream for about approximately ro $\mathrm{km}$ to the glacier terminus.

A very well developed set of wave ogives is found at the base of the Vaughan Lewis Icefall. An excellent aerial photograph of the ice fall and ogives was published by Miller ( 1963 ).

While doing ficld work in the ogive region we were impressed with the activity of the ice fall. It was decided that an interesting statistical study could be made in a rather short observation period. Consequently, observations were recorded from 20 August to 27 August 1967 , but with some interruptions caused by other field activities. We were interested in obtaining information concerning the following items: (1) the relative frequency of occurrence of avalanches of various magnitudes, (2) possible correlation of ice-fall activity with diurnal temperature changes or rate of change of temperature and, (3) the effect of a given ice fall in aiding the onset of a second ice fall which occurs shortly thereafter.

* Unfortunately the term "ice fall" has a dual usage among glaciologists. It refers to both the entire physical feature as well as the actual tumbling down of ice. However, the context should convey the intended meaning. 


\section{Observationat. Methods}

Data were collected in a very straightforward fashion. When an avalanche was observed, the time and an estimate of its magnitude were both recorded. It was found that recording the time to hall minute intervals was of sufficient accuracy. Whenever possible the approximate location of the avalanche and pertinent weather conditions were noted and recorded.

The magnitude scale was set in a rather elementary fashion. A very large avalanche was the first to be recorded and it was given a magnitude of "5". A relatively small avalanche was then given a rating of " $I$ ". However, it was found necessary to use half intervals such as " $1-2$ ", " $3-4$ ", etc. This effectively gave a scale with io divisions. Although this seems crude, it was found by experience to be rather precise. Visitors to our area were quickly "calibrated" to our magnitude scale after observing only a few avalanches. As glacier travel and work require at least two in a party, all of the magnitude estimates were based on the judgment of at least two observers. In all cases there was never more than one unit difference between the magnitudes suggested by the various observers.

\section{3.' Results}

Frequency-magnitude. A total of 186 avalanches were observed. During the most active day (24 h) a total of 55 avalanches were recorded. On the least active day only 26 events were observed.

Figure $\mathbf{I}$ is a plot of the relative frequency against the magnitude of the avalanche. Note that the data have a very small scatter about the smooth curve and, as expected, an inverse relationship is seen there.

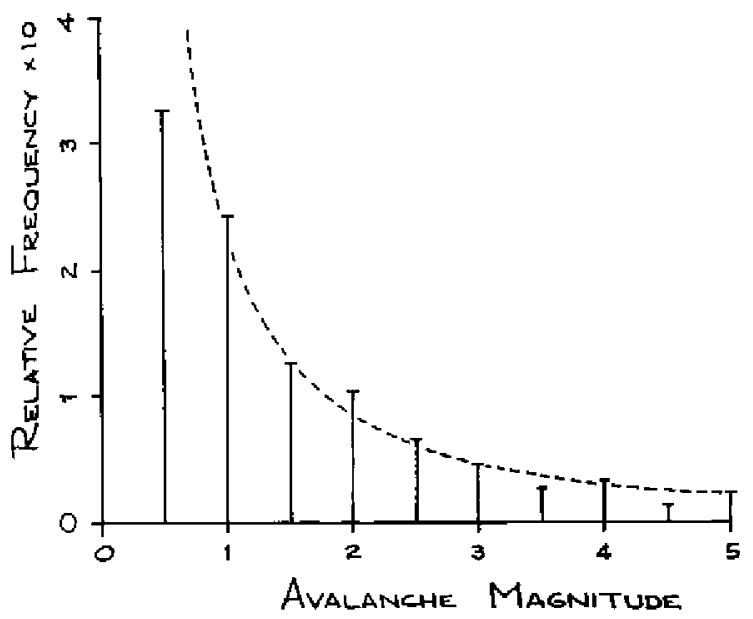

Fig. 1 . Observed varialion of relative frequency $f$ with avalanche magnitude $m$. Dolled curve is given by the equalion: $f=0.23 \mathrm{~m}^{3 / 2}$.

A plot of the relative frequency $f$ against avalanche magnitude $m$ on $\log -\log$ coordinates, shows a small scattcr aboul a straight line with a slope of -1.5 . This gives a relation of the form $f=0.23 / \mathrm{m}^{3 / 2}$ when $m$ can take all integer and half integer values from 0.5 to 5 .

At higher magnitudes the data have a littlc more scatter. This is attributed to the relativcly small number of avalanches observed at the larger magnitudes. In addition, the number of "o-I" magnitude avalanches appears to fall below the "best curve" drawn through the data. This effect may be due to the increased difficulty of detecting marginal movements in the 
ice fall. External effects such as wind noise, rain pelting on tents and parkas, the crunching of crampons on ice, cooking noises, conversation, etc., all contribute to obscuring a minimal avalanche from detection. It should be noted in this regard that the majority of the observations were only heard and not seen. This was the case as many avalanches were heard at night and under poor visibility conditions such as heavy rains or "white-outs".

Three zones of avalanche activity were delineated. On the right-hand side of the glacier, looking down-stream, hanging ice often broke loose and cascaded over a rock cliff (approximately $75 \mathrm{~m}$ high) to a lower position on the glacier. Activity in this area accounted for approximately 40 per cent of all avalanches observed. A similar cliff was located on the lefthand side and this location accounted for another 5 per cent. The remainder of the avalanches were found in the central portion of the ice fall or were not located because of restricted visibility conditions.

\section{Diurnal variation of avalanche frequency}

Data were collected into hourly intervals independent of magnitude. The raw data are given in Table I. Figure 2 shows the average number of avalanches per hour observed for each of the 24 hours of the day. The smaller number of observations of the various hour intervals requires that appropriate statistical tests be applied to the data to see if the data indicate statistically significant variations or if the differences could be merely due to small sample size and consequent random scatter.

Table 1. Number oy Avalanches Observed in Hourly Intervals

\begin{tabular}{|c|c|c|c|c|c|c|c|c|c|c|c|}
\hline \multicolumn{12}{|c|}{ Hour interval $(24 \mathrm{~h}$ clock $)$} \\
\hline $0-1$ & $1-2$ & $2-3$ & $3-4$ & $4^{-5}$ & $5-6$ & $6-7$ & 78 & $8-9$ & $9-10$ & $10-11$ & $11-12$ \\
\hline 1 & 4 & 2 & 4 & & 3 & 5 & 4 & to & 3 & 1 & 3 \\
\hline 1 & & I & & & 4 & 5 & 3 & o & 3 & 1 & 2 \\
\hline \multirow[t]{3}{*}{1} & & 2 & & & & & 1 & 3 & 2 & 0 & 1 \\
\hline & & & & & & & 1 & & 1 & 3 & 3 \\
\hline & & & & & & & & & & 3 & 1 \\
\hline \multicolumn{12}{|c|}{ Mean } \\
\hline 1 & 4.0 & 1.67 & 4.0 & - & $3 \cdot 5$ & 5.0 & 2.25 & $4 \cdot 33$ & 2.25 & 1.60 & 2.0 \\
\hline \multicolumn{12}{|c|}{ Hour interial $(24 h$ clock $)$} \\
\hline $12-13$ & $13-14$ & $14^{-15}$ & $15^{-16}$ & $16-17$ & $17-18$ & $18-19$ & $19-20$ & $20-21$ & $21-22$ & $22-23$ & $23-24$ \\
\hline 0 & 3 & 1 & 1 & 2 & 1 & 2 & 1 & 1 & $t$ & 2 & 1 \\
\hline 6 & $t$ & 3 & 1 & 0 & 5 & 3 & 0 & 5 & 4 & 2 & 1 \\
\hline 4 & 5 & 2 & 5 & 4 & 1 & 2 & 1 & 3 & $\mathrm{I}$ & 1 & \\
\hline I & 0 & $o$ & 4 & 0 & o & 1 & 0 & 1 & 3 & 1 & \\
\hline \multirow[t]{2}{*}{3} & I & 1 & 0 & 3 & o & 2 & 1 & 1 & & & \\
\hline & 1 & 0 & I & & 6 & & & & & & \\
\hline \multicolumn{12}{|c|}{ Mean } \\
\hline 2.80 & 1.84 & 1.16 & 2.0 & 1.8 & 2.17 & 2.0 & 0.6 & 2.2 & 2.25 & 1.5 & 1 \\
\hline
\end{tabular}

A Poisson type distribution should adequately describe the number of avalanches observed on different days at any given hour interval of the day unless the weather changes are considerable, e.g. in comparing summer and winter days. The criteria which must be satisfied for the application of Poisson statistics are the following:

(I) Events occurring in any given time interval are independent of those occurring in all other time intervals.

(2) The probability of observing an event is proportional to the duration of the observation period.

(3) It is unlikely that two or more events occur in the same time interval for the case of vanishingly small time intervals. 


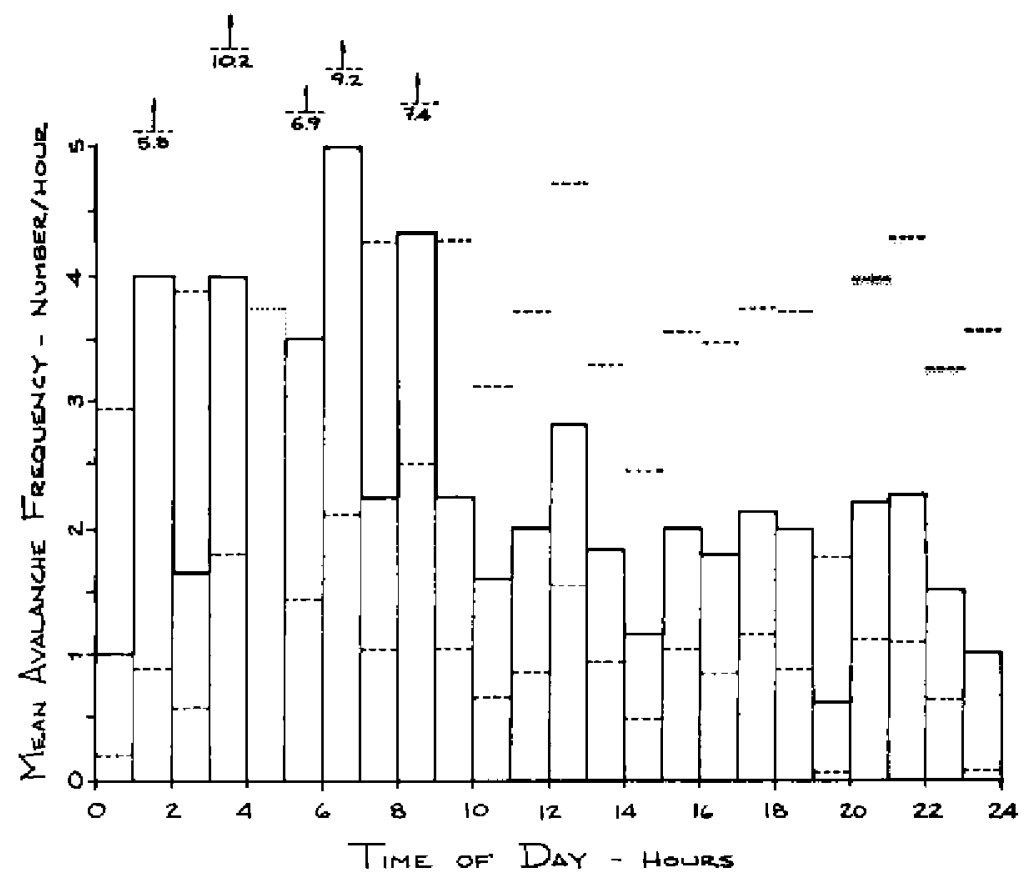

Fig. 2. Dinonal variation of atalanche frequency. Dashed lines indicate slatistical confidence $\left(95_{0}^{0}\right)$ intervals. Dotted line during of.0o-05.00 h period indicales average value of adjacent inlervals.

These conditions are all approximately satisfied in the case of ice-fall avalanches. Thus the probability $p$ that a given number of avalanches $x$ will be observed in some time interval is given by

$$
p(x ; \mu)=\frac{\mathrm{e}^{-\mu} \mu^{x}}{x !}
$$

where $\mu$ is the mean value expected for the interval in question.

It is possible to compute confidence intervals for the data given in Table 1 . Based on the Poisson model, a confidence interval at the 0.95 probability level was computed for each of the hourly periods and plotted as the dotted lines in Figure 2. (Appendix A gives the details of the computational method.)

As noted in Pigure 2, the confidence intervals for the largest and smallest values are nonoverlapping. 'This indicates that at least the extrcme values of the mean avalanche frequency are significantly different.

Another method may bc utilized to test for significant diurnal variations in the avalanche rate. The waiting time between successive ice falls is computed and then analyzed by methods suggested in Maguire and others (1952). If the expectation $E$ of ice falls per unit time is constant during some period the waiting times $\Delta t$ are exponentially distributed

$$
p(\Delta t)=E \mathrm{e}^{-E \Delta t}
$$

Figure 2 indicates that the periods $05.00-09.00 \mathrm{~h}$ and $17.00-2 \mathrm{I} .00 \mathrm{~h}$ should have considerably different values of $E$. If we assume that the mean value of $E$ may be treated as a constant valuc and also has a different magrnitude during the two aforementioned intervals, we can then computc confidence intervals for the expectation rates based on the respective values of $\overline{\Delta l}$. In addition we can also calculate the ratio of the two $E$ values. Details of these computations may be found in Appendix B. 
Confidence intervals at the 0.95 probability level are $10.2 \mathrm{~min} \leqslant \mathrm{r} / E_{\mathrm{m}} \leqslant 19.5 \mathrm{~min}$ and $19.7 \mathrm{~min} \leqslant \mathrm{r} / E_{\mathrm{c}} \leqslant 43.3 \mathrm{~min}$, where $E_{\mathrm{m}}$ and $E_{\mathrm{e}}$ refer to the aforementioned morning and evening periods respectively. In addition the ratio $E_{\mathrm{m}} / E_{\mathrm{e}} \geqslant 1.3$ at the 0.95 significance level. Thus we are confident that Figure 2 does represent a real diurnal variation in avalanche frequency.

The trend of Figure 2 shows only one maximum in the daily variation of avalanche frequency. We originally anticipated a morning and evening peak associated with the daily heating and cooling during these periods. This same opinion was also expressed by other scientists working in the vicinity of ice falls in the Alaska Range (personal communication from C. Thompson, 1967). However, they did not quantitatively record their observations. The only effect which seems to explain the single diurnal maximum in the avalanche frequency is the reduction of the air temperature below freezing.

This last effect was vividly demonstrated when a cloudy sky began to clear at approximately $03.00 \mathrm{~h}$ one morning. Radiation cooling quickly dropped the air temperature and the ice-fall activity increased from 2 per hour to $4-5$ per hour for the next several hours before returning to normal. Ice formation on crevasse pools indicated that the air temperature had fallen below freezing.

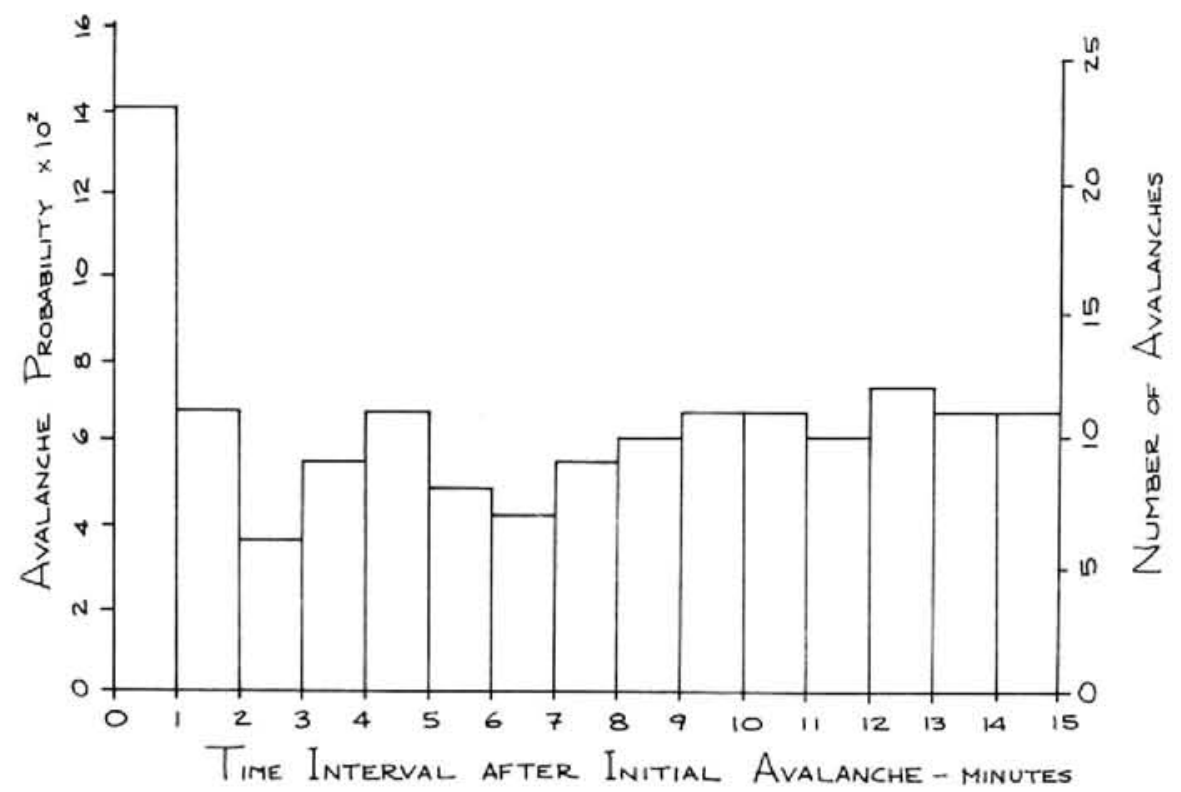

Fig. 3. Probability of avalanche during minute intervals following an initial avalanche. Data based on ${ }_{5} 59$ initial events.

Another unique incident was a period of overcast sky followed by a partly cloudy sky condition which finally was terminated by a light drizzle. Under the overcast sky the activity was I-2 per hour while the intermittent sunlight produced rates of 4 and 5 per hour. With the onset of rain, the activity returned to 2 per hour. Unfortunately, this sequence of weather conditions was only observed on one occasion. Thus it is not possible to conclude if this was a real phenomenon or just due to a fortuitous observation.

\section{Induced avalanches}

The question of induced ice-fall activity was perhaps the most interesting question we hoped to answer. Two opposing schools of thought were found among our colleagues. Both 
sides agreed that avalanches widely spaced in time should be completely uncorrelated. However, one school reasoned that a given ice fall removes loose and unstable material and thus the probability of another ice fall following soon thereafter is reduced. The opposing camp stated that the vibration associated with a given ice fall should loosen additional material which is then primed for the next ice fall. Thus one fall should induce another in short order.

Figure 3 supports the second contention. The probability of an avalanche occurring within the first minute is more than double the mean probability for the minute intervals from 4 to $15 \mathrm{~min}$ after the initial avalanche. In reducing the data, each avalanche was successively considered as an initial avalanche. The time interval to subsequent avalanches was calculated and recorded. Dividing the number of avalanches in any one minute time interval by the total number of avalanches considered gives the probability of an avalanche during that period. For example, Figure 3 shows that the probability of an avalanche during the $0-1 \mathrm{~min}$ interval after the initial ice fall is 0.14 . During the interval from $2-3 \mathrm{~min}$ the probability is reduced to 0.038 .

The statistical significance of the differences in probabilities shown in Figure 3 can be readily seen if a mean Poisson distribution is assumed for the number of avalanches observed in all time intervals. The mean number of avalanches for the intervals between 4 and $15 \mathrm{~min}$ is approximately 10 . Using this value of $\mu$ in the Poisson distribution we can estimate the probability of observing 23 or more avalanches as found in the $\mathrm{o}-1 \mathrm{~min}$ interval. From standard tables this result is

$$
\operatorname{Pr}(x \geqslant 23 ; 10)=\mathrm{I}-\sum_{x=0}^{22} p(x ; 10)=0.0003 .
$$

Thus it is very probable that the value of $\mu$ for the $0_{-1}$ min period is considerably greater than ro. Similarly the probability that the $2-3 \mathrm{~min}$ interval should contain 6 or fewer avalanches is

$$
\operatorname{Pr}(x \leqslant 6 ; \text { 10 })=\sum_{x=0}^{6} p(x ; 10)=0.13^{\circ},
$$

and this interval is also significantly different from the long-time mean.

If there were no correlation between any ice falls the probability would be equal for all periods. This seems to be the case for the periods from 4 to $15 \mathrm{~min}$ after the initial avalanche. No further change in the probability is anticipated for all later periods. The $2-3$ min interval is significantly lower than the $4^{-15}$ min mean probability. This seems to indicate that the second avalanche which occurs in the $0-1$ or $\mathrm{I}-2$ min interval succeeds in removing the material loosened by the first avalanche. Consequently, a relative dearth of avalanches is observed in the $2-3 \mathrm{~min}$ interval. As the probability is again at the mean value in the $3-4 \mathrm{~min}$ interval, the characteristic "memory" time of the ice fall is on the order of 3 to 4 min.

\section{Conclusions}

The relative avalanche frequency varies inversely with the magnitude of the avalanche. A single maximum was found for the diurnal variation of avalanche activity. This peak was apparently associated with a reduction in the air temperature below the freezing level. Vibration and the associated loosening of material caused by a given ice fall aids in producing another ice fall within the ensuing $2 \mathrm{~min}$ interval. After $4 \mathrm{~min}$ the effect of a given avalanche is erased from the ice fall's memory.

It would be very interesting to observe other ice falls to see if they exhibit the same characteristics as the Vaughan Lewis Icefall. As the observational procedures are relatively simple, the required data could be acquired by scientists performing other tasks in the vicinity of ice falls. 


\section{Acknowledgements}

The author wishes to thank Dr M. M. Miller, Director of the Glaciological and Arctic Sciences Institute for providing the opportunity and support required in making this study. Logistical support was provided through Michigan State University's affiliated National Geographic Society Alaskan Glacier Commemorative Project; field facilities by the Foundation for Glacier Research. Special thanks are also due to $\mathrm{Mr}$ Art Twomey who helped collect the field data and $\mathrm{Mr}$ Harte Bressler who aided in the preliminary data reduction. Dr John F. Nye of the University of Bristol is thanked for his review and comments on an earlier draft of this manuscript. It is with appreciation that we cite the indirect aid given by all the members of the 1967 Glaciological and Arctic Sciences Institute.

MS. received 16 January 1968 and in revised form 23.4 pril 1968

\section{REFERENCES}

Guenther. W. E. I965. Concepts of statistical inference. New York. McGraw-Hill.

Maguire, B. A., and others. 1952. The time intervals between industrial accidents, by B. A. Maguire, E. S. Pearson and A. H. A. Wynn. Biometrika. Vol. 39, Pt. 1-2, p. 168-80.

Miller, M. M. r963. The Vaughan Lewis Glacier, Juneau Iceficld. Alaska. Journal of Glaciology, Vol. 4, No. 36. p. $666-67$.

\section{APPENDIX A}

\section{Poisson Distribution Confidence Intervals}

If $x_{1}, x_{1}, \ldots, x_{n}$ are $n$ samples taken from some Poisson distribution then the best estimate for the mean of the unknown distribution is

$$
\hat{\mu}=\sum_{i=1}^{n} \frac{x_{i}}{n}=\frac{y}{n}
$$

A range for $\hat{\mu}$ can be determined if a certain confidence level is specified. As the confidence level is given by $\mathrm{I}-\alpha$, where $\alpha$ is the significance level, then the confidence interval is $\mu_{1} \leqslant \hat{\mu} \leqslant \mu_{\mathrm{U}}$ where,

$$
\begin{gathered}
\mu_{\mathrm{L}}=\frac{\chi_{2 y ; \alpha / z}^{2}}{2 n}, \\
\mu_{\mathrm{U}}=\frac{\chi_{2 y+2 ; 1-x / x}^{2}}{2 n},
\end{gathered}
$$

and $\chi_{i ; \beta}^{2}$ is the integrated chi-squared density function.

Details of this standard calculation are given by Guenther (1965).

\section{APPENDIX B}

\section{Statistical Tests Based on Warting Times}

Maguire and others (1952) have shown that $2 n E \Delta l$ is distributed as $\chi_{2 n}^{2}$ where $n$ is the number of samples used in computing $\overline{\Delta t}$. Thus it follows that

$$
\chi_{2 n ; \alpha / 2}^{2} \leqslant 2 n E \overline{\Delta t} \leqslant \chi_{2 n ; r-x / 2}^{2}
$$


at the $\alpha$ significance level. This result may be rewritten to find the confidence interval for $1 / E$ :

$$
\frac{2 n \Delta t}{\chi_{2 n ;,-\alpha / 2}^{2}} \leqslant \frac{1}{E} \leqslant \frac{2 n \Delta t}{\chi_{2 n ; \alpha / 2}^{2}} .
$$

In calculating $E_{\mathrm{m}}$ and $E_{\mathrm{e}}$ the following values were utilized:

$$
\overline{\Delta t}_{\mathrm{m}}=13.8 \mathrm{~min}, \quad 2 n_{\mathrm{m}}=72, \quad \overline{\Delta t}_{\mathrm{e}}=28.1 \mathrm{~min}, \quad 2 n_{\mathrm{e}}=50 .
$$

If the waiting times found during two different periods are distributed both independently and exponentially and if the expectation values $E$ are different during the two periods then the ratio $E_{1} \bar{\Delta}_{1} / E_{2} \Delta t_{2}$ has an $F$ distribution with $2 n_{1}$ and $2 n_{2}$ degrees of freedom. Thus it follows that

$$
F_{2 n_{*}, 2 n_{z} ; \alpha} \leqslant \frac{E_{\mathrm{t}} \overline{\Delta t_{1}}}{E_{2} \overline{\Delta t_{2}}}
$$

at the $\mathrm{I}-a$ probability level. And hence at this same confidence level

$$
\frac{E_{1}}{E_{2}} \geqslant \frac{\overline{\Delta t}_{2}}{\overline{\Delta t}_{1}} F_{2 n_{1}, 2 n_{2} ; \alpha^{*}}
$$

With the values given above and $\alpha=0.05$, Equation $\mathrm{B}_{4}$ was used to calculate the result $E_{\mathrm{m}} / E_{\mathrm{e}} \geqslant 1.30$ which was quoted in the text. 